\title{
NEW DEVELOPMENTS IN THE MODERNIZATION AND REPAIR OF HYDRAULIC EQUIPMENT \\ (from results of the Second Seminar on Hydraulics \\ in Magnitogorsk)
}

\begin{abstract}
The seminar involved the participation of specialists from more than forty metallurgical companies and machinery manufacturers in Russia (total attendance was 148). Experts from a dozen different Russian and foreign producers of hydraulic equipment gave presentations at the meeting.
\end{abstract}

On November 3-4 of 2004, the Magnitogorsk Teaching and Engineering Center and the Personal staff training facility of the Magnitogorsk Metallurgical Combine (MMK) convened the second seminar on the topic "Latest Advances in the Modernization and Repair of Hydraulic Equipment at Metallurgical Plants: Diagnosis and Servicing of Hydraulic Equipment."

The seminar involved the participation of specialists from forty metallurgical and machine plants in Russia (total attendance was 148). The presentations at the meeting were given by experts from a dozen different major companies in Russia and abroad that make hydraulic equipment.

The seminar was opened by V. V. Panov, Chief Mechanic at the MMK. Panov pointed to the increasing importance of hydraulic equipment in the metallurgical industry and, hence, the increasing problems associated with its servicing under warranty. More on the same topic was offered by V. V. Bodrov, General Director of the Teaching and Engineering Center (TEC). Bodrov gave his view of organizing the maintenance of hydraulically operated equipment, stating that the industry needs to set up specialized service centers at individual factories. Here, the lead organization (the TEC) would be responsible for managing and supervising this effort and training the necessary technicians. The first such center has already been established at the MMK in a collaboration with the firm SMS DEMAG, and work is being done on setting up a similar center at the Chelyabinsk Pipe Plant. Preparations are being made to also establish a center at the Nizhniy Tagil Metallurgical Combine and several other facilities.

The company Bosch-Rexroth (Germany) gave two reports on new advances it has made in the area of axial-piston pumps and proportional servo systems. For example, D. Scozarello described a modification made to the series-30 A4VS pumps to increase their service life. The company added reinforced forged slipper blocks and a reinforced cylinder neck and introduced an additional internal circulation system, a bolted connection for the distributing plate, and a special vane to uniformly distribute the flow of hydraulic fluid. The sealing of the pump was improved through the use of special bushings with a ceramic coating, reinforcement of the edges of the seals, and other changes.

This report offered an interesting new solution for the operation of central lubrication stations. The innovation is based on the use of DP regulators, which make it possible to evenly distribute the load on all pumps, ensure that they all have the same service life, reduce noise, and control the system from a single DBV channel.

One of the problems of interest to many of the mechanics that maintain metallurgical equipment is working with low-flammability liquids (HFC). Scozarello reported on a new line of pumps designed for operation with such liquids. The pumps have specially designed plummer bearings and an optimally designed distributing plate, which has made it possible to increase pumps' service life.

Translated from Metallurg, No. 3, pp. 41-42, March, 2005. 
Bosch-Rexroth is continuing its work on modifying medium-pressure pumps of the A10VSO type, which are widely used in metallurgy. In particular, the company has developed new housings with an optimal degree of rigidity and a reduced level of noise and vibration.

The presentation given by G. Widman devoted special attention to the latest findings made by Bosch-Rexroth in the area of proportional servo valves - 4WRKE, 4WRSE, 4WRTE, 4WRGE, 4WRDE, etc. Widman discussed features of these valves and criteria that can be used to choose the correct design for a given application.

All of the participants in the seminar also heard recommendations from Bosch-Rexroth representatives on the startup of new hydraulic systems at metallurgical plants.

M. Panke, Director of the company WEPUKO Hydraulik GmbH (Germany), noted that energy use should be optimized in order to minimize maintenance and repair costs. Panke described a hydromechanical unit for removing scale that is more productive than comparable mechanical devices and performs the job more efficiently while consuming less energy. The new unit has a unique bypass section consisting of two valves. Another topic of interest to listeners was a modified sinusoidal drive designed by Panke. The drive eliminates hydraulic shocks, reduces leakage, alleviates wear (pump service life ranges up to $80000 \mathrm{~h}$ ), provides for accurate stepped regulation of fluid flow in minimal time (within $100 \mathrm{msec}$ ), conserves energy, and reduces operating costs. Among the new products developed by WEPUKO are "intelligent pumps," which are radial-piston pumps with built-in electronic control systems.

The company SMS DEMAG (Germany) delivered three interesting reports. W. Sheffel discussed new approaches to monitoring the parameters of the hydraulic and mechanical elements of metallurgical equipment. These approaches involve the installation of special vibration pickups, temperature sensors, torque meters, data transmission equipment, a central server, and a special expert system. All this is making it possible to avoid accidents and to repair and replace equipment components based on their actual condition, rather than adhering to a preset schedule (the usual practice).

Attendees at the seminar were also interested in hearing Sheffel's report on the latest self-lubricating bearings. The special composite structure of the material of these bearings gives them the necessary mechanical strength and wear resistance at temperatures up to $320^{\circ} \mathrm{C}$. The bearings have a friction coefficient of $0.18-0.25$ and a compressive strength of $520 \mathrm{MPa}$. They undergo almost no creep, and their wear rate is substantially lower than comparable bearings. The use of such bearings obviates the need for lubrication systems.

G. Igelhorst discussed the work done by SMS DEMAG on the design, installation, and operation of hydraulic systems, giving special emphasis to systems designed to clean liquid lubricants and the company's latest inventions in this area.

G. W. Shepp presented a survey of units designed by the company INTERNORMEN to diagnose and repair oil lubrication systems. Of particular interest to the listeners were the units developed to remove water from hydraulic fluids, on-line units designed for the parallel filtration of counters that monitor particulate contamination of the fluids, and mini-laboratories for analyzing oil.

Of the greatest interest in the report given by W. A. Beck, General Director of the company Hudak International, was the information provided on portable meters of the HMG 2020 series. These meters are equipped with a set of transducers to measure pressure, temperature, flow rate, and frequency, a software package, a set of hydraulic adapters and measurement channels, and an inkjet printer. The meters offer a wide range of possibilities to technicians that service hydraulic metallurgical equipment. For example, they can be used to check pressure pulsations in a system, regulate the charging of hydraulic dampers to minimize such pulsations, and determine the volume efficiency of pumps.

S. I. Morin, Director of the Moscow affiliate of the company ECONOMOS (Austria), discussed new sealants and sealing systems. Seminar participants were especially interested in hearing from Morin about new designs of seals being used in mechanisms employed in ladles, continuous casters, pneumatic conveyors, and other types of equipment.

A. A. Baturin, Deputy Director of the "Pnevmostroimashina" company, talked about a new series of axial-piston pumps -410.56 and 410.107. Despite their smaller overall dimensions, the pumps were designed in such a way as to be able to attain new levels of working pressure (nominal $32 \mathrm{MPa}$, maximum $40 \mathrm{MPa}$ ). Also, the durability characteristics of the pumps are approximately 50\% higher than the analogous indices of standard hydraulic machinery. Trial batches of modernized serial machines with a maximum pressure of $40 \mathrm{MPa}$ are now being produced. 
Work is proceeding on the development of a new type of hydraulic pump with an inclined washer for use in closed systems. These pumps have working volumes of $90,112,125$, and $28 \mathrm{~cm}^{3}$ and are equipped with different types of regulators.

The report given by A. V. Druzhinin, Manager of the Parker company, described new types of hydraulic pipe joints with inset Ermeto EO Plus rings.

The brief presentation given by A. N. Ognev, an expert on lubrication systems with ExxonMobil, was devoted to new liquid lubricants for metallurgical equipment.

A roundtable was held at the end of the seminar for all of the presenters and audience members. Everyone who spoke at the roundtable commented on the usefulness of the seminar and recommended that it be continued on an annual basis. The main desire of the participants was that more technical information be given in the presentations made by companies. At the end of the meeting, all of the attendees received complete texts of the proceedings in Russian. Promotional materials and product catalogs were also made available.

The next seminar is planed for February 2006. Questions and suggestions on topics can be directed to the academic secretary of the seminar S. R. Sivrikova; t./f.: (3512) 750-172, 753-753; e-mail: sivrikova@cheltec.ru. 